\title{
Improved Transmission Path Visualization of Vibration Power Flow for Stiffened Plate Using Streamlines Representation
}

\author{
유선 표현법을 이용한 보강판의 진동파워흐름에 대한 \\ 개선된 전달경로 가시화
}

\author{
Noor Fawazi*, Un-Chang Jeong* and Jae-Eung $\mathrm{Oh}^{\dagger}$ \\ 누룰 파와지.정 운 창.오 재 응
}

(Received May 29, 2012 ; Accepted June 18, 2012)

Key Words : Vibration Intensity(진동 인텐시티), Vector Field(벡터장), Streamlines Visualization(유선 가시 화), Transmission Paths(전달경로)

\begin{abstract}
Vibration intensity has been used to localize vibration source of a vibrating system. Not only that, vibration intensity has also been used for structural diagnostic in identifying crack and mounted stiffeners. To clearly identify the location of vibration source and understand the changes of energy transmission path, clear flow visualization is required. Most of previous works used vectors to indicate the magnitude and direction of emerging vibration energy and transmission paths. However, due to the large surface area of a plate like-structure, clear transmission paths cannot be achieved using vector visualization. This becomes an issue when detail vector flow at all locations of the whole plate surface is required. In this study, streamlines visualization is used to clearly indicate the power flow transmission path at all plate surface. By using streamlines representation, not only clear transmission paths are obtained, but also improves the vector visualization which helps us to understand the changes of the energy flow especially for stiffened plates. In this study, vibration intensity computation is firstly compared to previous work to validate the vibration intensity computation. To clearly show the power flow transmission paths, streamlines representation is shown. This representation overcomes the unclear vector direction especially for stiffened plates. Different pattern of energy transmission path can be observed using streamlines representation for stiffened and unstiffened plate. The complex streamlines pattern can also be observed at high resonance frequencies which is unclear by using vector representation.
\end{abstract}

\section{요 약}

진동 인텐시티는 진동시스템의 원인을 찾는데 사용되어 왔다. 그 뿐만 아니라, 균열의 확인과 보 강재 설치와 같은 구조물의 진단에 사용되어 왔다. 진동원의 위치를 명확하게 파악하고 에너지 전 달경로의 변화를 이해하기 위해, 유동 가시화가 필요하다. 이전 연구의 대부분은 진동에너지의

$\dagger$ Corresponding Author; Member, School of Mechanical Engineering, Hanyang Uni.

E-mail : jeoh@hanyang.ac.kr
Tel : (02)2294-8294, Fax : (02)2299-3153

* Member, Graduate School of Mechanical Eng., Hanyang Uni. 
크기와 방향, 전달경로를 가리키는 벡터를 사용하였다. 그러나, 판과 같은 구조물의 넓은 면적으로 인해 벡터 가시화를 사용하여 명확한 전달경로를 알아낼 수 없었다. 이것은 전체 판 표면에 대한 상세한 벡터 흐름이 필요한 경우에 문제가 된다. 이 연구에서는 명확하게 모든 판 표면의 파워 흐 름 전달경로를 표시하기 위해 유선 가시화가 사용되었다. 유선 가시화를 사용함으로써, 분명한 전달 경로를 얻을 수 있을 뿐만 아니라 보강판의 에너지 흐름 변화를 이해하는데 도움이 되어 벡터 가시 화를 향상시킬 수 있다. 우선 진동 인텐시티 계산의 검증을 위해 이전 연구와 비교를 한다. 명확하 게 파워 흐름 전달경로를 표시하기 위해 유선표현을 사용하였다. 이 표현법은 보강판의 분명하지 않은 벡터 방향을 보완해 준다. 보강판과 보강되지 않은 판의 에너지 전달경로의 패턴 차이를 유선 표현법을 사용하여 확인할 수 있다. 복잡한 유선 패턴은 벡터표현으로 분명하지 않은 높은 공진주 파수에서 확인할 수 있다.

\section{Appendix}

E : Elastic modulus

$I_{x}, I_{y}, I_{z} \quad$ : Components of vibration intensity

$M_{x}, M_{y}, M_{x y}$ : Complex bending and twisting moment

$N_{x}, N_{x y}$ : Complex membrane forces

$Q_{x}, Q_{y}$ : Complex transverse shear forces

$\sigma_{k l} \quad$ : Complex stress

$v_{l} \quad$ : Complex velocity

$\mu \quad$ : Poisson's ratio

\section{Introduction}

Vibration intensity can be defined as the vibrational power flow per unit cross-sectional area of a dynamically loaded elastic body ${ }^{(1,2)}$. This is analogous to acoustic intensity in a fluid medium. Vibration intensity computation has become a great interest for practical reasons.

Vibration intensity field shows the magnitude and direction of vibration energy flow in structural vibration at any point in structure. The vibration intensity vectors express the energy transmission paths and reveal the location of vibration source and sinks. For vibration reduction, it is important to specify vibration propagation paths and vibration sources. Besides identifying the location of source and sink, vibration intensity field using vectors has been used for structural diag- nostic such as crack and mounted stiffness identification. The changes of the vibration intensity vectors help us to identify any regions of vibrating surface that are cracked or mounted with stiffeners ${ }^{(3)}$.

However, due to the large surface area of any plate-like structure, clear transmission paths of vibration energy cannot be achieved using vectors. Due to small magnitude of vectors, clear transmission path cannot be achieved. It is therefore, accurate transmission path information cannot be obtained.

In this study, the idea of field lines is used to overcome such problem. Streamlines in a vector field is drawn so that the direction at any point is the same as the direction of the field at that point. This streamlines visualization helps us to understand and obtain clear information on vibrational energy flow especially for complex structure such as stiffened plate which is not yet considered in any previous work. Previous works never highlights the use of streamlines to improve the vibration energy transmission paths especially for stiffened plate. By using streamlines visualization, the changes of vibration energy transmission paths can be clearly understood in comparison to conventional vector visualization. With the changes of streamlines, not only the source and sinking location can be localized, the areas that are mounted with stiffener can also be identified. 


\section{Theoretical Background}

The instantaneous vibration intensity component in the time domain can be defined as ${ }^{(1)}$

$$
i_{k}(t)=-\sigma_{k l}(t) v_{l}(t)
$$

where $\sigma_{k l}(t)$ and $v_{l}(t)$ are the time history of stress and velocity in the $l$-th direction.

The vibration intensity can be expressed in the form of the net energy flow per-unit width for shells and plates. The energy flow lies in the plane tangential to the midsurface of the structure. Displacements of any point of a thin-walled structure can be expressed by translational and angular displacements of the midsurface as shown in Fig. 1. The two components of the vibration intensity for a flat thin plate are as follows ${ }^{(1)}$.

$$
\begin{aligned}
& I_{x}=-\frac{\omega}{2} \operatorname{Im}\left[N_{x} u^{*}+N_{x y} v^{*}+Q_{x} w^{*}+M_{x} \theta_{y}^{*}-M_{x y} \theta_{x}^{*}\right] \\
& I_{y}=-\frac{\omega}{2} \operatorname{Im}\left[N_{y} u^{*}+N_{y x} v^{*}+Q_{y} w^{*}+M_{y} \theta_{x}^{*}-M_{y x} \theta_{y}^{*}\right]
\end{aligned}
$$

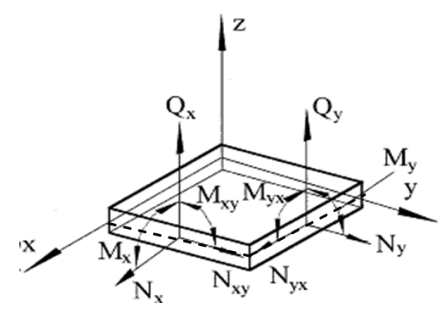

(a) Moment and forces

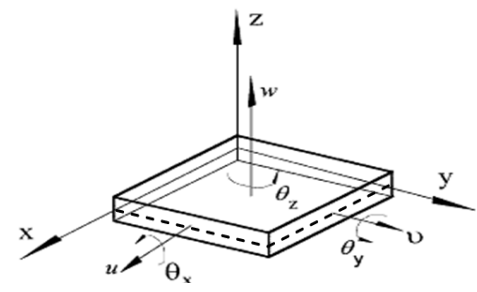

(b) Displacements

Fig. 1 Stress resultants, translational and angular displacements where $N_{x}, N_{y}$ and $N_{x y}=N_{y x}$ are complex membrane forces per unit width of the plate, $M_{x}, M_{y}$ and $M_{x y}=M_{y x}$ are complex bending and twisting moments per unit width of the plate, $Q_{x}$ and $Q_{y}$ are complex transverses shear forces per unit width of the plate, $u^{*}, v^{*}$ and $w^{*}$ are complex conjugates of translational displacements in $x, y$ and $z$ directions, $\theta_{x}$ and $\theta_{y}$ are complex conjugates of rotational displacement about the $x$ and $y$ directions $^{(1 \sim 7)}$.

The streamlines representation shows the flow as lines at any location parallel to the velocity field. The relative spacing of the lines indicates the speed of the flow. The vibration intensity streamline can be defined as

$$
d \vec{r} \times \vec{I}(\vec{r}, t)=0
$$

where $\vec{r}$ is the energy flow particle position. For the steady state energy flows the cross product can be written as

$$
\left|\begin{array}{ccc}
\vec{i} & \vec{j} & \vec{k} \\
I_{x} & I_{y} & I_{z} \\
d x & d y & d z
\end{array}\right|=0
$$

Thus, for 2-dimensional plate structures, the differential equation describing a streamline is

$$
\frac{d x}{I_{x}}=\frac{d y}{I_{y}}
$$

\section{Computation Method}

Finite element computations for vibration intensity were reported in references ${ }^{(4,5)}$. Different commercial packages were used for calculating the field variables of the model.

In this study, the full method for harmonic response solution was used for the calculation of the vibration intensity to predict energy flow in an elastic plate. Unlike the mode superposition, 
full matrices of the system were used with no simplification. It is directly calculated from the mass, damping, and stiffness matrices of the model. This computation can be more expensive in terms of time, but by using this computation more accurate results can be obtained since modal truncations were not included. The commercial finite element analysis code MSC NASTRAN was used for all calculations in this study.

\subsection{Model for Computational Validation}

To validate the vibration intensity computation, similar example to previous work ${ }^{(1)}$ was firstly computed. This computation was carried out on a simply supported thin Aluminum plate which was $0.707 \mathrm{~m}$ long and $0.5 \mathrm{~m}$ wide with a thickness of $3 \mathrm{~mm}$. The material properties used for the plate were as follows: the Young's Modulus is 70000 $\mathrm{MPa}$, the Poisson ratio is 0.3 and the mass density is $2100 \mathrm{~kg} / \mathrm{m}^{2}$.

A constant damping ratio of 0.005 was used and a central point excitation with amplitude of $1 \mathrm{~N}$ was applied perpendicular to the surface of the plate as shown in Fig. 2.

\subsection{Model for Streamlines Calculation}

In this study, the effects of the existence of stiffeners are considered. Although the energy flows in the stiffeners are very important, only the vibration intensity within plate is considered. The vibration intensity fields are then plotted using vectors and streamlines.

All simply supported $6 \mathrm{~mm}$ thickness Steel plate was chosen for these streamlines computations. The

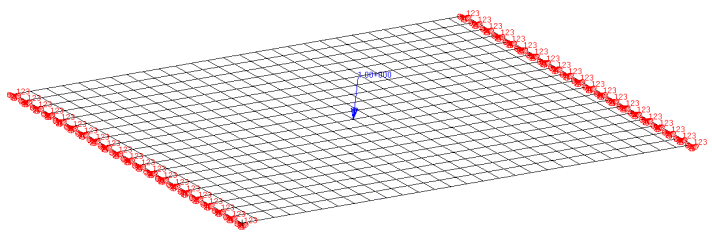

Fig. 2 Finite element model of a simply supported plate $^{(1)}$ material properties of this model are: the Young's modulus is $205.8 \mathrm{GPa}$, the Poisson ratio is 0.3 and the mass density is $7800 \mathrm{~kg} / \mathrm{m}^{2}$. For each case, an exciting force with a magnitude of $1 \mathrm{~N}$ with different excitation frequencies was employed as shown in Table 1. In the computations, all plates were excited at low and high frequencies to examine whether there were different pattern of vibration energy transmission paths due to frequency on the intensity vectors.

Low and high resonance frequencies were considered in order to investigate the changes of vibration intensity fields. These excitation frequencies were close to the fundamental structural vibration frequencies for each plate. A viscous damper(external damper) with a damping rate of $2000 \mathrm{Ns} / \mathrm{m}$ is applied as shown in Fig. 3.

The excitation frequency is analogous to many kinds of dynamic load or pressure excitations. For instance, a sailing ship that is always exposed to the waves of sea, the stiffened plates of side hull is subjected to periodical actions from sea wave pressure and hydrodynamic impact. The excitations frequencies will be changed very much from slowly varying load to rapidly varying load. It is therefore, in our study, the load exciting frequencies were purposely defined close to the fundamental structural vibration of each case.

An additional external damper as shown in Fig. 3 to Fig. 6 represents the presence of a dissipative element which can be used to simulate some particular structure such as loosed bolt ${ }^{(3)}$. Vibration energy tends to be dissipated in such vibrating system. In vibration analysis, detail transmission

Table 1 Fundamental N.F for all cases(N.F : natural freq.)

\begin{tabular}{c|c|c|c|c|c}
\hline \hline No. & Case(s) & $\begin{array}{c}\text { Plate } \\
\text { (no stiffener) } \\
{[\mathrm{Hz}]}\end{array}$ & $\begin{array}{c}\text { Plate (1) } \\
{[\mathrm{Hz}]}\end{array}$ & $\begin{array}{c}\text { Plate (2) } \\
{[\mathrm{Hz}]}\end{array}$ & $\begin{array}{c}\text { Plate (3) } \\
{[\mathrm{Hz}]}\end{array}$ \\
\hline 1. & Low N.F & 19.58 & 27.51 & 22.54 & 31.7 \\
\hline 2. & $\begin{array}{c}\text { High } \\
\text { N.F }\end{array}$ & 76.02 & 75.32 & 72.12 & 73.54 \\
\hline
\end{tabular}



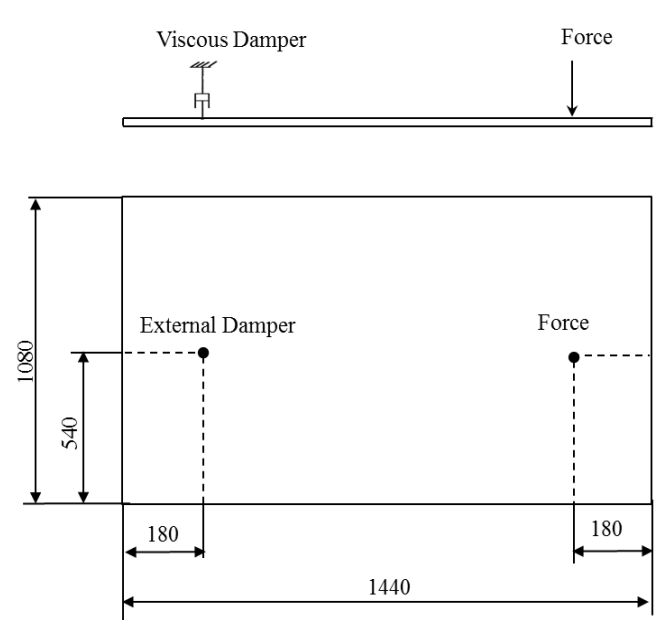

Fig. 3 Plate without stiffener
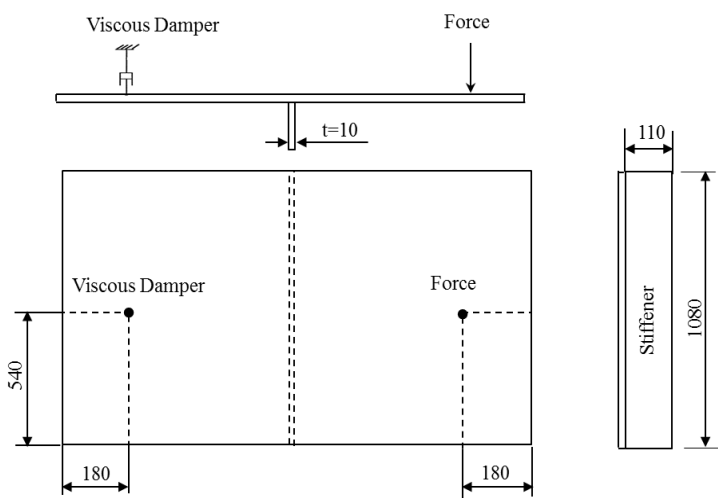

Fig. 4 Plate with stiffener 1

path of power flow from the source to any dissipative element is greatly important. This example is chosen to investigate the effectiveness of streamlines representation at providing detail information on the transmission of power flow.

To show the advantage of vector flow using streamlines visualization, three cases of plates with different attached stiffeners positions were considered as shown in Fig. 4 to Fig. 6. Similar material properties were used for all stiffeners. The position of the exciting force and external damper were purposely located symmetrical to each other. This was done to investigate the changes flow pattern between the exciting force and external viscous damper.
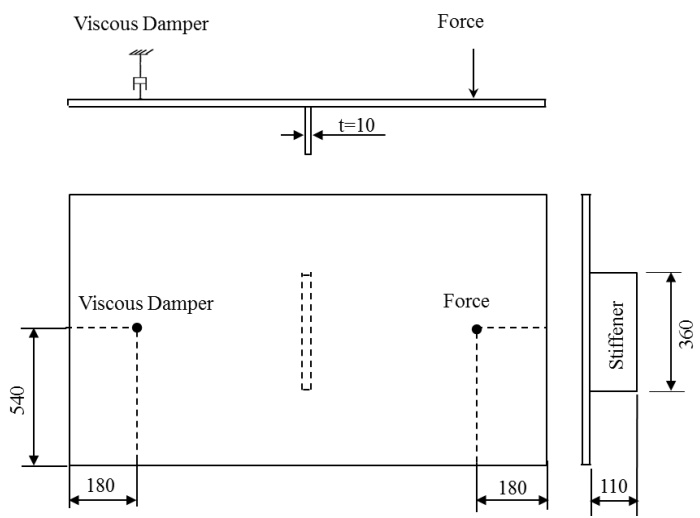

Fig. 5 Plate with stiffener 2
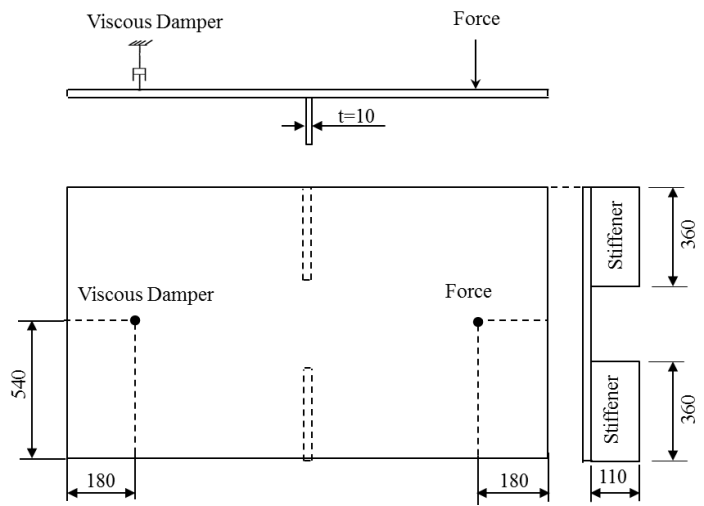

Fig. 6 Plate with stiffeners 3

\section{Computation Results}

Figure 7 compares the calculated vector flow between the present computation and previous work $^{(1)}$. Similar pattern of vector flow is observed. This computation result clearly shows the source of power flow at the center of the plate at $14 \mathrm{~Hz}$.

The directions of the vector flows are clear within the location where the point excitation is applied. This is because of the high vibration energy. However, this vector flow visualization fails to provide detail transmission path at all locations. The directions of the vectors become ambiguous at the region where the magnitude of energy vibration is lower. The small magnitude of 


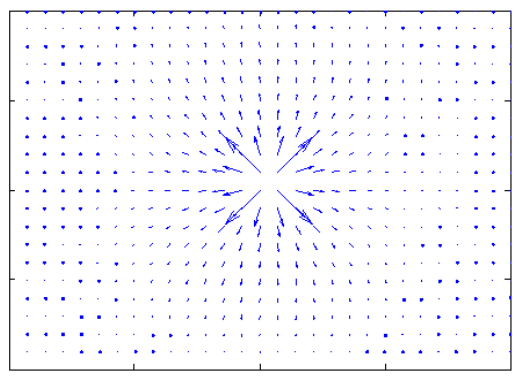

(a)

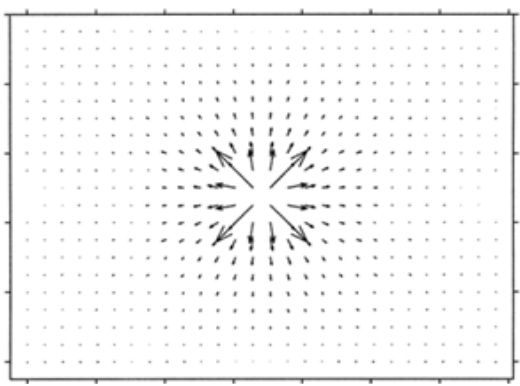

(b)

Fig. 7 Comparison of (a) plotted vector intensity flow to (b) reference ${ }^{(1)}$ at $14 \mathrm{~Hz}$

the vector cannot provide accurate direction of the vibration energy transmission paths.

Fig. 8 shows the computation result using vector flow and streamlines representation for an unstiffened plate at $19.58 \mathrm{~Hz}$. The location of vibration source and dissipative damping element can be identified using vector representation. However, the transmission paths information between the two positions is quite ambiguous. In comparison to the streamlines representation, not only the location of source and damping elements are revealed, but also clear pattern of transmission paths between the exciting force and damping element can be obtained. From streamlines representation, it is easier to examine the energy flow transmission path, especially to visually follow the generation process of energy vortices.

With the increment of resonance frequency or at high excitation frequency $(76.02 \mathrm{~Hz})$, similarly the location of vibration source and source are revealed. This is shown in Fig. 9. By using

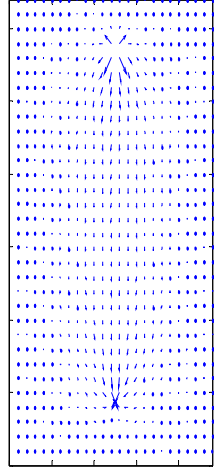

(a)

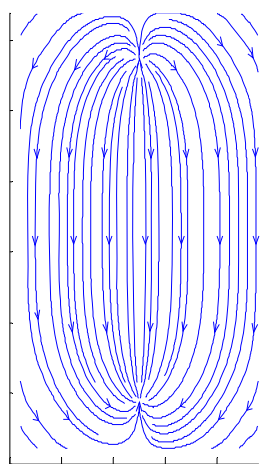

(b)
Fig. 8 Plate without stiffener (a) vector flow (b) streamlines computations at $19.58 \mathrm{~Hz}$

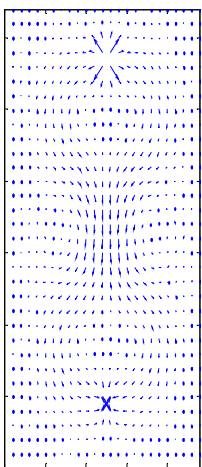

(a)

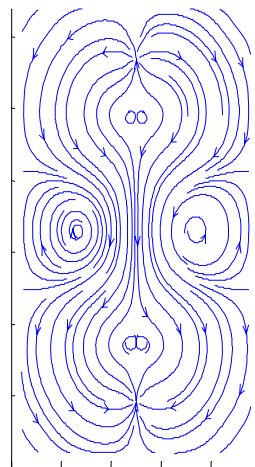

(b)
Fig. 9 Plate without stiffener (a) vector flow (b) streamlines computations at $76.02 \mathrm{~Hz}$

streamlines visualization, clear complex transmission paths can be observed in comparison to vibration intensity field using vectors.

Figure 10 shows the computation result of a plate where a $10 \mathrm{~mm}$ thickness stiffener is attached between the source and dissipative element. By using vibration vector flow visualization, the location of exciting source and dissipative element(external damper) can be observed. In comparison to the streamlines representation, despite the existence of stiffener within the plate, the vibration intensity streamlines visualization not only clearly indicates the source and the sink position, but also the transmission of energy flow. 
Figure 10 to Fig. 15 clearly shows the changes of vibration intensity patterns in stiffened plate at

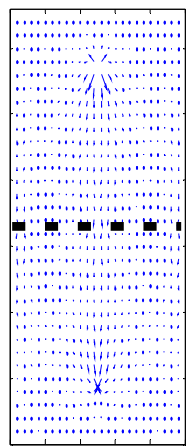

(a)

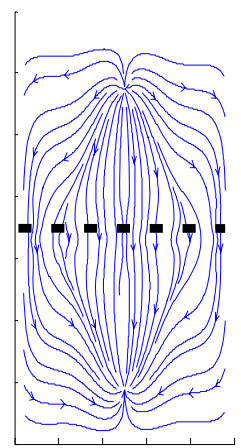

(b)
Fig. 10 Plate (1) with stiffener (a) vector flow (b) streamlines computations at $27.51 \mathrm{~Hz}$

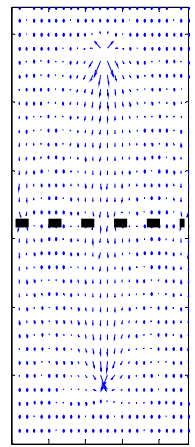

(a)

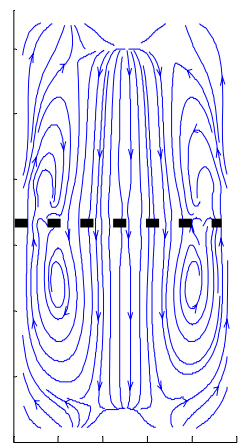

(b)
Fig. 11 Plate (1) with stiffener (a) vector flow (b) streamlines computation at $75.32 \mathrm{~Hz}$

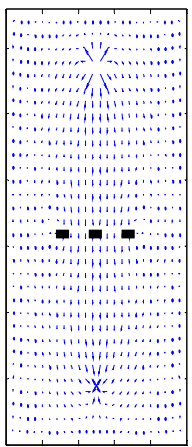

(a)

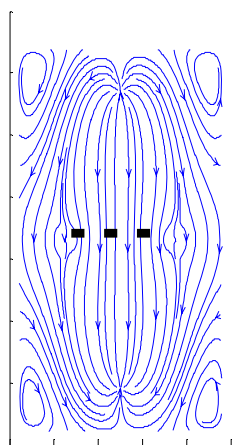

(b)
Fig. 12 Plate (2) with stiffener (a) vector flow (b) streamlines computations at $22.54 \mathrm{~Hz}$

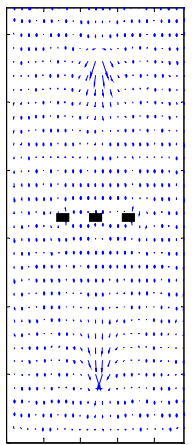

(a)

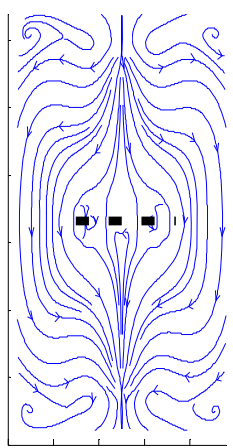

(b) respected resonance frequencies. These changes are influenced by the different way of attaching the

Fig. 13 Plate (2) with stiffener (a) vector flow (b) streamlines computations at $72.12 \mathrm{~Hz}$

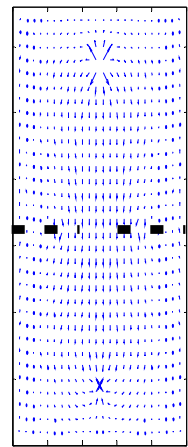

(a)

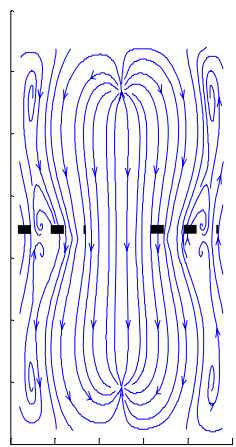

(b)
Fig. 14 Plate (3) with stiffener (a) vector flow (b) streamlines computations at $31.70 \mathrm{~Hz}$

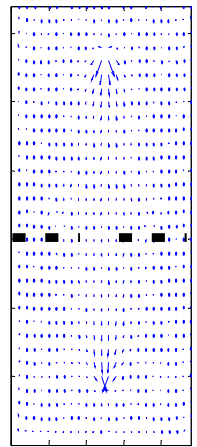

(a)

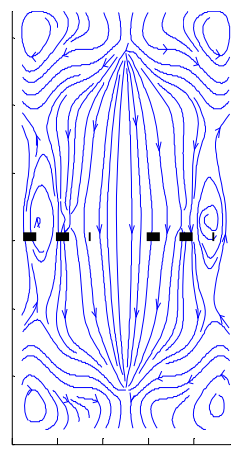

(b)
Fig. 15 Plate (3) with stiffener (a) vector flow (b) streamlines computations at $73.54 \mathrm{~Hz}$ 
stiffeners. The detail flow representation can be only achieved using the streamlines. Significant different flow patterns can be observed from the unstiffened plate and stiffened plate. Based on the streamline representation, a uniform vibration intensity flow can be observed from the unstiffened plate. However, with the variation of attached stiffeners, a significant flow changes can be observed at the area where the stiffeners are attached.

Similarly, at high resonance frequency, clear complex transmission paths are observed.

\section{Conclusion}

This study improves the vibration intensity field using streamlines representation. A clear vibration power flow transmission paths can be achieved using streamlines representation. This is important to show the vortex and the energy dissipation through any dissipative element.

In this study, the flow of vibration energy for various stiffened plate are also considered. The streamlines representation clearly shows a better flow curve at all locations. This clear representation cannot be obtained from a vector flow representation. The direction of the transmission path is ambiguous at many other regions. Streamlines representation can be the best alternative especially for large plates with a number of stiffeners where the directions of all transmission paths can be identified. Not only that, the streamlines provide better visualization than the vector flow in general.

The changes of the streamlines representation provide us information on the existence of attached stiffeners. Undeniably, the vector flow can also indicate the stiffener's location. However, the streamlines representation is very clear for stiffened and unstiffened plate at first glance in comparison to the vector flow representation.

Significant different transmission paths of vi- bration energy can be observed with the increment of resonance frequencies. Again, the streamlines visualization provides clear transmission paths.

Although the streamlines cannot indicate the relative magnitudes of vibration intensities, this representation provides a better means of visualizing the dominant power flow paths.

\section{Further Study}

Experimental work will be considered for further study. The focus will be on the streamlines visualization from an experimental works. This has never been highlighted in any previous work.

The streamlines computation can also be used for a large plate with a number of cracks. The changed patterns using streamlines can be useful as a reference to diagnose plate with no crack and a plate with crack.

Detail study on the stiffeners arrangement and geometric properties of the stiffeners can also be conducted using this streamlines visualization especially to design large plate like-structure with a number of stiffeners.

\section{References}

(1) Li, Y. J., 1999, Prediction of Surface Mobility of a Finite Plate with Uniform Force Excitation by Structural Intensity, Applied Acoustic, Vol. 60, pp. 371 383.

(2) Xu, X. D., 2004, The Energy Flow Analysis in Stiffened Plates of Marine Structures, Thin-walled Structures, Vol. 42, pp. 979 994.

(3) Khun, M. S., 2003, Structural Intensity in Plate with Multiple Discrete and Distributed Spring-dashpot Systems, Thin-walled Structures, Vol. 42, pp. 979 994.

(4) Hambric, S. A., 1990, Power Flow and Mechanical Intensity Calculations in Structural Finite Element Analysis, Journal of Vibration and Acoustics 
112, pp. 542 549.

(5) Gavric, L. and Pavic, G., 1993, A Finite Element Method for Computation of Structural Intensity by the Normal Mode Approach, Journal of Sound and Vibration, Vol. 164, No. 1, pp. 29 43.

(6) Oh, J.-E., Fawazi, N., Gwak, H.-T., Jeong, U.-C. and Lee, J.-Y., 2011, Vibration Intensity Computation of a Single Plate with Uniform Force
Excitation Using FEM, Proceedings of the KSNVE Annual Autumn Conference, pp. 392 393.

(7) Fawazi, N., Yoon, J.-H., Lee, J.-Y. and Oh, J.-E., 2009, Identification of Exciting Source Location of a Vibrating Plate Using Vibration Intensity, Proceedings of the KSNVE Annual Spring Conference, pp. 222 223. 